(c) American Dairy Science Association, 2004.

\title{
Applied Genetic Evaluations for Production and Functional Traits in Dairy Cattle
}

\author{
T. Mark \\ Interbull Centre \\ Department of Animal Breeding and Genetics, \\ Swedish University of Agricultural Sciences, 75007 Uppsala
}

\section{ABSTRACT}

The objective of this study was to review the current status of genetic evaluation systems for production and functional traits as practiced in different Interbull member countries and to discuss that status in relation to research results and potential improvements. Thirtyone countries provided information. Substantial variation was evident for number of traits considered per country, trait definition, genetic evaluation procedure within trait, effects included, and how these were treated in genetic evaluation models. All countries lacked genetic evaluations for one or more economically important traits. Improvement in the genetic evaluation models, especially for many functional traits, could be achieved by closing the gaps between research and practice. More detailed and up to date information about national genetic evaluation systems for traits in different countries is available at www.interbull.org. Female fertility and workability traits were considered in many countries and could be next in line for international genetic evaluations.

(Key words: Genetic evaluation, functional traits, across-country genetic correlations, variance heterogeneity)

Abbreviation key: WHFF $=$ World Holstein Friesian Federation.

\section{INTRODUCTION}

Data used in genetic evaluations for dairy cattle are typically characterized by country. Performance records on individual animals collected within country or within a limited number of neighboring countries are typically stored in a national database. With a few noticeable exceptions, the data are owned by farmer organizations. Genetic evaluations follow the flow of data from milk recordings, national breed associations, arti-

Received November 25, 2003.

Accepted March 28, 2004.

E-mail: Thomas.Mark@hgen.slu.se. ficial insemination organizations, classifiers, slaughterhouses, veterinarians, and individual farmers. Today, only few examples exist of joint national genetic evaluations and of regional genetic evaluations.

Genetic evaluations have undergone steady development during the past half century. More traits are being evaluated and more sophisticated evaluation methods are being implemented. The evolvement of genetic evaluations has taken a variety of directions pending on local know-how, data availability, resources, priorities, and other factors. Some countries have prioritized very sophisticated methods for single traits of high economic importance, whereas others have strived to undertake genetic evaluations for a larger number of traits.

Dairy cattle breeding has become increasingly international during the past few decades. International trade in genetic material (e.g., embryos, livestock, and especially semen) has intensified, and genetic evaluations are no longer only of national concern. Today, across-country genetic evaluations for all genetic traits of economic importance are desired. International genetic evaluations are being conducted for dairy production, conformation, and udder health traits. Longevity and calving traits are in the pipeline, but international genetic evaluations for other functional traits are also in demand. The term "functional traits" will be used here to summarize those characters of an animal that increase efficiency not by higher outputs of products but by reduced costs of input (Groen et al., 1997).

International genetic evaluations are currently being computed in two steps. First, national genetic evaluations are being computed in several countries. Secondly, deregressed national genetic evaluation results, free of all nongenetic effects, are used as dependent variables in a multiple-trait model with each country considered as a separate trait (Schaeffer, 1994; Banos and Sigurdsson, 1996). Thus, national breeding values must be unbiased, and all nongenetic effects on raw performance are assumed to be accounted for in the national evaluations. The international genetic evaluation is the final step, but the majority of resources are available and are being used at national levels. 
Transparency and discussions with international colleagues are instrumental for national genetic evaluation units in ensuring high-quality unbiased national genetic evaluations. Furthermore, across-country selection is more efficient when the genetic correlations between similar traits measured in different countries are high. Again, trait harmonization is important to achieve this, and transparency of national genetic evaluation systems is the first requirement to facilitate such harmonization. Knowledge of the status and dissemination of national genetic evaluations is therefore needed in preparation for new international genetic evaluations, and such knowledge is also important in improving already existing genetic evaluations.

Genetic evaluation practices have previously been summarized. The most recent survey for dairy production traits was carried out in 1999 (Interbull, 2000), and the latest survey for growth and beef production and functional traits was carried out in 1995 (Interbull, 1996). These surveys showed that genetic evaluation practices varied greatly between countries, but the differences were not formally discussed in relation to published research results.

The objective of this study was to give an overview and to increase transparency of current (national) genetic evaluations as practiced in different Interbull member countries. A second objective was to discuss research results pointing to areas where either national genetic evaluations could be improved or the degree of harmonization of the evaluations implemented in different countries could be increased. This survey will mainly focus on applied genetic evaluation models and trait definitions. Less focus will be on preevaluation steps, the combination of traits into indexes and publication details, although these are also important aspects of genetic evaluation systems and deserve more attention.

\section{MATERIALS AND METHODS}

A questionnaire was sent to all 49 Interbull member organizations. These organizations corresponded to 41 countries, since some countries had more than one member organization. These were all breed specific. Thirty-nine member organizations replied to the questionnaire (31 countries) or the Interbull Center had similar information available from previous surveys (Interbull, 1996, 2000). Supplemental information were collected from proceedings of Interbull open meetings and in references indicated in specific replies.

For simplicity, this survey mainly summarizes information by country and does not distinguish between differences in genetic evaluations for different breeds. Only in a few cases did the information differ between breeds within country. In these cases, the breed with the most complete information or most advanced methodology was chosen. The term "country" will be used to describe the geographical region covered by a genetic evaluation, irrespective of whether the genetic evaluation only covered a region of a country (e.g., the Walloon region of Belgium). Countries participating in a joint national genetic evaluation will be treated separately (e.g., Austria and Germany).

The information collected was not always as complete and easy to interpret as one could have wished, but in most cases, the information was of high quality. Stimulating factors were that the information is being actively used to promote the respective genetic evaluations via the Interbull Web site (www.interbull.org), and that this information was required for participation in Interbull evaluations. Thus, dairy production, conformation, and udder health descriptions for countries participating in these evaluations must be available and up to date. It is possible that information from nonparticipating countries and for other traits was not made available to Interbull or was not completely up to date. The information, upon which this survey was based, was taken from the Interbull Web site on August 25, 2003. This information is continuously being updated with new and revised information.

A copy of the questionnaire (Form GE) and an accompanying guide are also available on the Interbull Web site. The questions covered details such as trait definitions, data collection, data edits, preadjustments, genetic model, genetic parameters, reliability computation, expression of genetic merit, use in indexes, and publication details. All dairy breeds and all traits considered were covered. Traits were classified according to the following 10 main trait groups: dairy production, conformation, health, longevity, calving, female fertility, workability, beef production, efficiency, and other traits. Subtraits belonging to each of these main categories were included.

This survey was not representative of genetic evaluation systems as applied globally. Rather, it was a survey of practices of countries with more developed genetic evaluation systems, since these countries would typically be Interbull members and were more likely to reply to the questionnaire.

\section{RESULTS}

Table 1 gives an overview of the dissemination of national genetic evaluations for different traits. All 31 countries that made information available had genetic evaluations for dairy production traits and the majority of countries (26) also analyzed a wide range of different conformation traits. Genetic evaluations for important 
Table 1. Heritability and dissemination of genetic evaluations for different main trait groups.

\begin{tabular}{lccc}
\hline & $\begin{array}{l}\text { Number of } \\
\text { countries with } \\
\text { at least one } \\
\text { evaluation }\end{array}$ & $\begin{array}{l}\text { Number of } \\
\text { subtraits }\end{array}$ & \\
country & Heritability \\
\hline Trait group & 31 & $1-15$ & $0.19-0.59$ \\
Dairy production & 26 & $14-33$ & $0.04-0.64$ \\
Conformation & 19 & $1-15$ & $0.01-0.43$ \\
Health & 14 & $1-7$ & $0.02-0.18$ \\
Longevity & 14 & $1-8$ & $0.01-0.13$ \\
Calving & 14 & $1-6$ & $0.01-0.07$ \\
Female fertility & 13 & $1-4$ & $0.05-0.35$ \\
Workability & 5 & $2-10$ & $0.13-0.36$ \\
Beef production & 2 & 1 & $0.33-0.40$ \\
Efficiency & 3 & 1 & 0.02 \\
Other traits & 3 & &
\end{tabular}

${ }^{1}$ Each parity was counted when they were treated as different traits.

functional traits, such as health, longevity, calving, and workability traits, were also widely considered in national genetic evaluation programs (12 to 19 countries). The number of traits being evaluated in a country was 31.2 on average, and ranged from 1 to 61 . The number of main trait groups with at least one genetic evaluation was 4.5 on average and ranged from 1 to 9. Only a few countries reported to have national genetic evaluations for beef production (5), efficiency (2), and other traits (3). Therefore, the latter traits will not be dealt with in much detail. Furthermore, dairy production traits and nondairy production traits will be treated separately. More details will be provided for dairy production traits as they are more widely considered and are generally considered to be of the highest economic importance.

\section{National Genetic Evaluations for Dairy Production Traits}

Trait definitions and data included. Dairy production traits considered in various countries were rather homogeneously defined. The following 7 dairy production traits were considered: milk yield, fat yield, protein yield, fat percentage, protein percentage, SNF yield, and SNF percentage. Sources of variation in trait definitions included number of parities, days after calving, data edits, and extension rules. For example, the number of parities considered ranged from 1 to all (median $=3$ ) and up to $330 \mathrm{~d}$ after calving was considered, whereas only the first $305 \mathrm{~d}$ after calving was most commonly used to define the production trait. Some countries, however, used test day information from up to $365 \mathrm{~d}$ after calving to predict the 305-d yield. Most countries considered a sum of test day yields per lactation. Others considered yields at each test day as the trait of interest.
Genetic models. Table 2 gives an overview of effects included in different national genetic evaluation models for milk production and how these effects were treated in the model. A variety of different effects were included in national genetic evaluation models. Most countries used animal models for dairy production traits. However, one country still used a sire model. Three other countries included a random sire $\times$ herd interaction as an explanatory effect in their animal model. Most countries assigned unknown parents to fixed genetic groups to account for selection among the unknown parents.

All countries accounted for herds in one way or another. The herd effect was mostly considered a fixed classification factor in the model, but some countries considered it as a random effect and some also considered it in multiplicative preadjustments. Furthermore, 6 countries considered herds as a random effect. Two countries using a test-day model treated herds as a random regression coefficient, but most countries treated herds as a class variable. Many different environmental effects were considered in different national genetic evaluation models in a number of different interaction combinations.

Adjustment for variance heterogeneity. Six countries simultaneously accounted for heterogeneous variances caused entirely by nongenetic factors, such as herd-year effects, when computing solutions to the evaluation model. Four countries had implemented a simple multiplicative model that scaled all fixed and random effects with a specific subclass constant equal to the residual variance ratio for that particular subclass (Meuwissen et al., 1996). An auto-correlative structure for (e.g., herd-year variances within herd) was further introduced for this approach to improve the precision of herd-year variance estimates by utilizing correlated information from proximate years. 
Table 2. Frequency ${ }^{1}$ and way of treating different effects in 31 national genetic milk production evaluations.

\begin{tabular}{|c|c|c|c|c|c|c|}
\hline \multirow[b]{3}{*}{ Effect } & \multirow{2}{*}{\multicolumn{2}{|c|}{ Pre-adjustment }} & \multicolumn{2}{|c|}{ Fixed effect in model } & \multicolumn{2}{|c|}{ Random effect in mode } \\
\hline & & & \multirow{2}{*}{$\begin{array}{l}\text { Class } \\
\text { variable }^{2}\end{array}$} & \multirow{2}{*}{$\begin{array}{l}\text { Regression } \\
\text { coefficient }\end{array}$} & \multirow{2}{*}{$\begin{array}{l}\text { Class } \\
\text { variable }\end{array}$} & \multirow{2}{*}{$\begin{array}{l}\text { Regression } \\
\text { coefficient }\end{array}$} \\
\hline & Additive $^{2}$ & Multiplicative & & & & \\
\hline Animal & & & & & 23 & 6 \\
\hline Sire & & & & & 4 & \\
\hline Genetic group & & & 27 & & & \\
\hline Permanent environment & & & & & 13 & 6 \\
\hline Herd, management group & & 6 & 30 & & 4 & 2 \\
\hline Region & & & 7 & 2 & & \\
\hline Season, calving month & 2 & 5 & 25 & 3 & & \\
\hline Year & & & 22 & & & 2 \\
\hline Test-day & & 4 & 7 & & & \\
\hline Lactation stage & 2 & 3 & 5 & 1 & & \\
\hline Age & 8 & 5 & 16 & 3 & & \\
\hline Parity & 2 & 2 & 18 & 4 & 1 & 3 \\
\hline Days pregnant & & & 3 & & & \\
\hline Milking frequency & 1 & 4 & 1 & & & \\
\hline Altitude & & & & 1 & & \\
\hline Induced lactation & & & 1 & & & \\
\hline Production level, parity 1 & & & 1 & & & \\
\hline Heterosis, recombination & 1 & 2 & 3 & 1 & & \\
\hline Breed & 1 & & 1 & 2 & & \\
\hline Length of dry period & & & 2 & & & \\
\hline Days open & 5 & 2 & 1 & 1 & & \\
\hline Calving interval & 3 & 1 & 2 & 4 & & \\
\hline
\end{tabular}

\footnotetext{
${ }^{1}$ An effect that appears in several different interaction combinations is only counted once per different kind of treatment.

${ }^{2}$ Assumed, unless otherwise stated.
}

France has implemented a model wherein random effects are normally distributed with heterogeneous residual variances (Robert-Cranié et al., 1999). In this model, fixed contemporary effects and random residuals were unadjusted, whereas genetic and permanent environmental effects were adjusted for heterogeneous residual variances. The adjustment for genetic and permanent environment effects was scaled differently according to known functions of homogeneous heritability and repeatability. However, results of the French model were very similar to the results of the Meuwissen-model (Robert-Cranié et al., 1999).

Most countries only accounted for heterogeneous residual or phenotypic variances. The United States accounted for both heterogeneous genetic and residual variances (Wiggans and VanRaden, 1991), but ignored covariances because of genetic relationships and reduction in variance due to selection. The definitions for subclasses differed across country, but usually variances were assumed to be heterogeneous across different herds, years, and parities.

A total of 20 countries applied preadjustments of the dependent variable prior to genetic evaluation. Eleven countries reported doing a multiplicative preadjustment (i.e., adjusted for both means and variances). Two countries had both a simultaneous adjustment and preadjustment for heterogeneous variance.

\section{National Genetic Evaluations for Nondairy Production Traits}

Many of the conclusions regarding applied genetic evaluations for dairy production traits were also valid for functional and other nondairy production traits. Often the discrepancies between countries were even larger for functional traits, which could be due to much less attention on these traits (at least until recently) and the often complex nature of various functional traits leading to many possibilities for defining and analyzing these traits. A careful examination of all evaluations in all countries would be too exhausting, and similar issues would be brought up repeatedly. Only a brief overview with a focus on trait definitions and evaluation models will be given.

Trait definitions and data included. A large range of conformation traits was considered and evaluated in most countries. They were primarily visually scored and were primarily based on first parity. The World Holstein Friesian Federation (WHFF) has made a substantial effort to harmonize trait definitions of linearly scored conformation in different countries. Other breeds (e.g., Ayrshire) have followed the definitions outlined by WHFF. Thus, conformation traits were expected to be similarly defined across most countries, and to some extent, also across breeds. Changes 
in trait definitions have, however, resulted in problems with consistency of trait definition in adjacent time periods (de Jong and Harbers, 2002), which will cause problems as long as trait harmonizations are ongoing.

Trait definitions for SCC differed with respect to the number of parities considered and as to whether lactation-sums or test-day yields were considered (mostly 3 parities were considered, but ranged from 1 to 5 parities). Two of the Nordic countries only considered SCC records from the first half of the lactation period, and others considered records from up to $365 \mathrm{~d}$ after calving. Most countries considered up to $305 \mathrm{~d}$ of lactation. The Nordic countries had direct genetic evaluations for resistance to a range of different clinical disorders; including clinical mastitis, metabolic diseases, reproductive diseases and disorders, feet and leg diseases and disorders, and diseases other than mastitis and fertility disorders. They were all defined as binary traits (i.e., either the presence or absence of disease during specific time intervals), but trait definitions were generally not well harmonized across country. Differences included which disorders were included in each trait and whether culling reasons were considered.

Trait definitions for longevity included the number of days from first calving to culling or final milk record, the number of days from first calving to culling (uncensored) or to actual date (right censored data), reappearance in a subsequent lactation (binary trait with missing observation if no opportunity to reappear), and months in milk (e.g., truncated at $7 \mathrm{yr}$ of age and 305 $\mathrm{d}$ per lactation). Longevity can either be defined as true longevity (i.e., unadjusted and reflecting ability to delay culling), functional longevity (i.e., corrected for milk yield and reflecting ability to delay involuntary disposal), or residual longevity (i.e., corrected for all other traits considered in breeding program). Functional longevity was most common. A variety of different predictors were used to define combined longevity (selection index or multiple-trait BLUP). These included conformation traits, dairy production traits, SCC, maternal calving ease, calving interval minus days to first insemination, and milking speed besides direct longevity information, which is mainly available late in an animal's life.

Calving ease was defined with subjective terms (e.g., easy or hard calving). The number of categories ranged from 2 to 5, although some countries may merge categories with very low frequencies before genetic evaluation. The number of parities considered ranged from first to all parities. First and later parities were often regarded as different traits, and both direct and maternal calving ease were typically considered. The same was the case for stillbirth, except that the definition was more objec- tive. It was a binary trait with calves being either dead or alive $24 \mathrm{~h}$ or later postpartum.

Female fertility is a complex trait group and several fertility measures could be and were considered. Consequently, a very broad range of different traits was defined for genetic evaluations in different countries, and many countries evaluated more than one trait. No single measure seemed to describe all genetic variation associated with the whole female fertility complex. The different fertility traits, which were considered in different countries, could be classified as follows: 1) ability to conceive: non-return rate (e.g., within $56 \mathrm{~d}$ from first insemination), days from first to last insemination, conception rate (yes or no) at each insemination, the number of AI until pregnancy or per insemination period, and bearing of calf in herds insemination period (yes or no); 2) ability to return to estrus: days from calving to first insemination, cow presented for mating within $21 \mathrm{~d}$ (yes or no), heat strength (subjectively scored), and fertility treatments (yes or no); and 3) a combination of measures 1 and 2: days from calving to last insemination or pregnancy (days open) and calving interval.

Furthermore, some countries used functions of the above trait definitions to simplify (farmers) interpretation, but this did not change the trait genetically. For example, the United States reported genetic evaluations for days open as "daughter pregnancy rate," which is simply calculated as a linear function of days open. Heifer and cow fertility was often distinguished as different traits.

Workability traits considered for genetic evaluation in different countries included the following categorical traits: milking speed, temperament, leakage, adaptability to milking routine after calving, and farmers overall acceptance. Again, the number of categories varied (5 to 9). In 2 countries (with joint genetic evaluation), milking speed was defined as a continuous trait (volume per time unit). Such trait definitions will likely become more common as milk meters become more commonly available. Only information from first parity was considered for workability traits in the majority of countries.

The beef production traits that were reported included daily gain, carcass value, carcass classification (e.g., EUROP grading system), muscularity, meatiness, fat coverage, meat color, and percentage of kidney fat. In some cases, different traits were considered depending on the type of animal: cows, calves, or steers. Efficiency included live weight of cows, and BCS was used as a predictor trait. Feed conversion rate is a trait of very high economic importance, but reported measures did not seem to capture much of the relevant genetic variation for feed conversion rate. Other traits 
Table 3. Number of countries with certain model features ${ }^{1}$ for different main trait groups.

\begin{tabular}{lrrrrrrr}
\hline & \multicolumn{7}{c}{ Model feature } \\
\cline { 2 - 7 } Main trait group & SM & AM & ST & MT & TDM & Survival & Threshold \\
\hline Dairy production & 1 & 30 & 20 & 11 & 8 & & \\
Conformation & 1 & 25 & 15 & 11 & & & \\
Health & 3 & 16 & 9 & 10 & 11 & & \\
Longevity & 9 & 5 & 11 & 3 & & & \\
Calving & 11 & 3 & 7 & 7 & & \\
Female fertility & 7 & 7 & 7 & 7 & & \\
Workability & 4 & 9 & 9 & 4 & & \\
Beef production & 5 & & 3 & 2 & & & \\
Efficiency & 1 & 2 & 2 & & & & \\
Other traits & & 2 & 1 & 2 & & & \\
\hline
\end{tabular}

\footnotetext{
${ }^{1}$ Model features: $\mathrm{SM}=$ sire model, $\mathrm{AM}=$ animal model, $\mathrm{ST}=$ single-trait, $\mathrm{MT}$ = multiple-trait (includes
} multiple parities treated as different traits), TDM = test-day model.

considered were male fertility and persistency of lactation.

Genetic models. Table 3 gives an overview of applied genetic models for functional traits (production traits are included for comparison). Sire models were more widely used for genetic evaluations of functional traits compared with dairy production traits. The percentage of countries applying a sire model was 64, 79 and 50\% for longevity, calving, and female fertility, respectively. Genetic evaluations of conformation, SCC, and workability traits were mainly done using animal models. Test-day models were more widespread for SCC than for dairy production (11 and 8 countries, respectively). Relatively few countries have implemented threshold models for analysis of categorical traits. Only 2 countries used a threshold model for calving, one used a threshold model for workability, and no countries used a threshold model for analysis of binary health traits.

Use of genetic groups and adjustment for heterogeneous variance was less widespread for functional traits compared with dairy production traits. Simultaneous heterogeneity adjustment during calculation of solutions to the evaluation model was especially rare.

\section{Across-Country Genetic Correlations}

The across-country genetic correlations (Table 4) provide some indication of the degree of harmonization of trait definitions and evaluation procedures across countries.

Across-country genetic correlations for dairy production, SCC, and many linear conformation traits were

Table 4. Average and range in genetic correlations $\left(\mathrm{r}_{\mathrm{G}}\right)$ across different Holstein populations for different traits.

\begin{tabular}{|c|c|c|c|c|c|}
\hline \multirow[b]{2}{*}{ Trait } & \multirow[b]{2}{*}{ Populations } & \multicolumn{2}{|c|}{ All populations } & \multicolumn{2}{|c|}{ Seven core populations ${ }^{1}$} \\
\hline & & Mean $r_{G}$ & Range of $r_{G}$ & Mean $r_{G}$ & Range of $r_{G}$ \\
\hline Milk yield $^{2}$ & 27 & 0.88 & 0.20 & 0.92 & 0.08 \\
\hline Fat yield ${ }^{2}$ & 27 & 0.87 & 0.20 & 0.92 & 0.07 \\
\hline Protein yield ${ }^{2}$ & 27 & 0.87 & 0.20 & 0.92 & 0.08 \\
\hline Stature $^{2}$ & 21 & 0.89 & 0.39 & 0.94 & 0.15 \\
\hline Fore udder attachment ${ }^{2}$ & 21 & 0.75 & 0.82 & 0.82 & 0.34 \\
\hline 15 linear-type traits ${ }^{2}$ & $17-21$ & 0.81 & 0.91 & 0.87 & 0.48 \\
\hline $\mathrm{SCC}^{2}$ & 20 & 0.85 & 0.41 & 0.90 & 0.14 \\
\hline Clinical mastitis $^{2}$ & 4 & 0.74 & 0.25 & $\ldots$ & $\ldots$ \\
\hline Longevity $^{3}$ & 14 & 0.59 & 0.96 & 0.71 & 0.51 \\
\hline Direct calving ease $^{4}$ & 10 & 0.83 & 0.45 & 0.83 & 0.39 \\
\hline Maternal calving ease ${ }^{4}$ & 10 & 0.58 & 0.97 & 0.84 & 0.36 \\
\hline Direct stillbirth $^{4}$ & 7 & 0.64 & 0.66 & $\ldots$ & $\ldots$ \\
\hline Maternal stillbirth ${ }^{4}$ & 7 & 0.59 & 0.87 & $\ldots$ & $\ldots$ \\
\hline
\end{tabular}

\footnotetext{
${ }^{1}$ Those populations that had evaluations for all traits, except clinical mastitis and stillbirth (i.e., Canada Germany, Denmark, France, The Netherlands, Sweden, and United States).

${ }^{2}$ Genetic correlations as used in Interbull August 2003 evaluations.

${ }^{3}$ Genetic correlations for direct longevity from Jakobsen (2003).

${ }^{4}$ Genetic correlations from Jakobsen et al. (2003).
} 
high on average. Estimated correlations for direct longevity varied considerably and were low regardless of the method used for national genetic evaluation. Calving ease in different countries was more closely correlated than longevity, but the estimated correlations also varied considerably.

\section{DISCUSSION}

The number of traits evaluated per main trait group or per country was not necessarily indicative of the degree of coverage of total aggregate genetic merit by genetic evaluations as the economic value of different traits differs. For instance, having different genetic evaluations for SCC in 3 different parities is not necessarily better than having one genetic evaluation for SCC and one for clinical mastitis. No country had complete coverage of total aggregate genetic merit by genetic evaluations assuming that all main trait groups (except beef production) have at least some economic importance in each country. Many countries were not even close to it.

National genetic evaluation units have limited resources and need to prioritize between traits and models. The choice between different traits (e.g., whether to further develop the model for evaluation of dairy production traits or to implement a model for a new trait) is not always straightforward. Here one needs to assess the expected marginal increase in genetic progress for total aggregate genetic merit that can be obtained by improving the existing evaluation with the expected increase in aggregate genetic progress that can be obtained by introducing a genetic evaluation for the new trait.

Choice of model for a particular trait is not only a matter of how well the model fits the data. It is also important that the model has few parameters, a high degree of genetic variance explained by genetic effects, a good predictive ability, and is simple to implement, maintain, and use. The genetic response, which can be achieved for the true trait of economic importance by using a particular model, is of main interest, but is not realistic to assess for many models.

The choice of best method and model is trait dependent. Different traits have different distributional properties, relations with other traits, selection pressure, etc., and this means that what is best for one trait cannot necessarily be generalized to other traits. To some extent, the choice can also be country dependent, at least with respect to effects included in the model. Generally, it is unlikely that a single model performs best in all countries due to very different local circumstances. Whereas local circumstances may justify many of the observed differences in national genetic models, it seems there were too many differences and that harmonization could lead to better national and international genetic evaluations.

In the following sections, dairy production and other traits will be discussed separately. Some specific differences in evaluation models for dairy production traits will be discussed, whereas the discussion about other traits will focus on differences of the methods applied. Some explanatory effects included in different national genetic evaluations differ for obvious reasons. For example, heterosis effects should only be included when there is a significant amount of information available from crossbred animals, and effects of altitude should only be included when altitude affects the phenotype (e.g., for countries with latitude differences). Also, in some countries, herd sizes are too small to allow a fixed effect of herd-year-season in the model. In other cases, the reason for the differences is not obvious and these will be discussed later.

\section{Best Practice for Dairy Production Traits}

The Interbull Guidelines (Interbull, 2001) states that an animal model is better than a sire model, a multipletrait model is better than a single-trait model, a multiple-lactation model is better than a repeatability model, and a test-day model is better than a lactation-sum model.

Whereas most geneticists would agree with these recommendations (at least under the assumption of correct genetic parameters and for a continuous trait), it may be more difficult in some situations to choose between a single-trait animal model and a multiple-trait sire model. The Interbull Guidelines do not provide much help with such choices. However, with the substantial selection pressure on dairy production traits, it is crucial to include female relationships in the model as well as male relationships. In comparison, relatively little seems to be gained from multiple-trait analyses (i.e., of milk, fat, and protein yield) as these traits typically have similarly high heritabilities and information becomes available at the same time. However, multipletrait models are important when fewer protein records are available compared with milk and fat records.

The best potential method used for genetic evaluation of dairy production traits was the multiple-trait random regression test-day animal model. The random effects can be modeled in a number of alternative ways though (Jensen, 2001). In addition, many environmental effects, functions, etc., can be fitted to data. Advantages of test-day models compared with lactation-sum models include the ability to simultaneously account for environmental effects of each test-day, model lactation trajectories for specific genotypes, and the possibility of 
accessing persistency of milk production during lactation. The main disadvantages include increased computational requirements and more assumptions needed (e.g., more genetic parameters). Legal issues, such as patents, may inhibit use of appropriate models in some instances.

Sire $\times$ herd interaction. Including sire $\times$ herd interaction effects in the model may correct for differences among progeny groups in different herds due to management, but it may also capture valuable genetic variation in the herd $\times$ sire interaction instead of the animal effect. The latter would prevent inflation of additive genetic variance, but in the presence of a genotype $\times$ environment interaction, a multiple-trait model or reaction norm model (Kolmodin et al., 2002) allowing for different genotypic expression in different environments could be considered as an alternative to the single-trait model across different environments.

Contemporary group assumptions. Contemporary group effects were most frequently assumed to be fixed. Treating the groups as random effects can be advantageous, when group sizes are small, to recover information across groups (Visscher and Goddard, 1993). However, lower prediction error variance may be gained at the expense of bias due to nonrandom association between animals and contemporary groups. Van Bebber et al. (1997) reviewed advantages and disadvantages of different assumptions regarding contemporary group effects. They recommend using fixed contemporary group effects when the size of contemporary groups is approximately 15 effective daughters or more. Otherwise, it may be better to assume random contemporary groups depending on the specific population considered.

Genetic group assumptions. Accounting for selection among unknown parents is especially important for dairy production traits because these are subject to strong selection. Countries generally treated genetic groups as fixed effects. Care should be given to avoid small fixed genetic groups that are difficult to precisely infer. It may be advantageous to consider genetic groups as random effects, especially in situations with low heritability (Sullivan and Schaeffer, 1994) or when small group sizes cannot be avoided. Changes in genetic group solutions are a typical explanation for substantial deviations in predicted genetic merits between subsequent genetic evaluations.

Adjustment for variance heterogeneity. Both genetic and residual variances are often heterogeneous across environments and time. Failure to account for this in the evaluation model leads to biased results. This is particularly the case for elite cows, since sires usually have progeny in several environments (RobertCranié et al., 1999).
Adjustments done to observations prior to genetic evaluation are inadequate when the heterogeneity depends on effects in the genetic model. In such cases, simultaneous estimation of dispersion and location parameters is preferable. Strictly, the genetic evaluation is no longer BLUP when preadjustments are applied and all effects should preferably be included in the model whenever possible.

The aim of accounting for variance heterogeneity in the evaluation model is to reduce bias by better fulfilling the assumptions of the evaluation model. The validity (e.g., goodness of fit and predictive ability) of the models is often unknown. However, Meuwissen et al. (1996) reported that realized genetic merits were on average closer to parent averages for the model correcting for variance heterogeneity compared with a model that had no such correction. This was a reassuring property favoring the model correcting for variance heterogeneity. The same conclusion could likely be made for other populations as well, but the validity of the adjustments should be tested for the concerned population.

Fixed effects with a genetic interpretation. A few countries included genetic traits, such as number of days open and calving interval, in their genetic evaluation model for dairy production traits as a fixed explanatory effect. Whereas it is important to account for the fact that poor reproductive performance enables the cow to keep producing at a high level in later stages of lactation, this is not an optimal practice as it eliminates genetic variance of interest. The information could be better used in, for example, a multiple-trait analysis. However, selection for increased milk production would result in an indirect selection against fertility if no adjustment is made.

\section{Best Practice for Nondairy Production Traits}

Identification of best practice and choice of method seems more complex for functional traits compared with dairy production traits. There is no single model or method that is best for all functional traits. The traits differ considerably with respect to distributional properties of phenotypic expression, degree of selection pressure, heritability, and correlated traits. This needs to be taken into consideration when choosing the method of analysis.

Genetic effects. Sire models were still much more commonly applied for functional traits than for dairy production traits. This can be due to the fact that functional traits have received less priority, but it can also be because a sire model is the best practical alternative for many traits. Being able to include more predictor traits in a multiple-trait evaluation is often more important than accounting for preferential mating if the 
trait is subject to little selection, the majority of the information becomes available late in the animal's life, or if the genetic merit of the females is of little interest due to low precision (e.g., caused by low heritability). This illustrates that finding the best practical evaluation method for a particular trait always involves compromises as it is not possible to evaluate all correlated traits simultaneously and certainly not in an animal model. Thus different compromises need to be made depending on the nature of each trait.

Categorical traits. The distribution of the dependent variable is important in choosing the best method. Application of animal models to categorical traits has proven problematic because of the "extreme category problem," wherein all observations for some subclasses are in the same category (e.g., Harville and Mee, 1984; Hoeschele and Tier, 1995). Luo et al. (2001) showed that a threshold animal model had problems with convergence and yielded biased parameters if convergence was reached when applied to categorical data. In contrast, parameters were unbiased when obtained with a threshold sire model. They further found that including a continuous trait with higher heritability and a high genetic correlation with the categorical trait decreased the variance of parameters. Boettcher et al. (1999) also found similar problems when attempting to apply an animal model to estimate genetic parameters for binary longevity data. They found that the herdyear and additive genetic variances were biased upwards with respect to the true residual variance when an animal model was used for prediction of longevity breeding values. Consequently, the correlation between breeding values from a linear sire model and breeding values from a similar animal model was as low as 0.87 .

Ramirez-Valverde et al. (2001) compared animal vs. sire models and threshold vs. linear models by correlations between breeding values predicted from 2 different samples of Gelbvieh calving data. They found higher correlations for animal models compared with sire models, similar correlations for univariate linear and univariate threshold models and higher correlations for bivariate threshold compared with bivariate linear models (linear effect of birth weight included in both bivariate analysis).

However, even in sire models, extreme categories may pose problems. Therefore, Harville and Mee (1984) suggested replacing the fixed herd-year-season effect with the sum of a fixed season effect and a random herd-year effect while letting herd-year effects follow a first-order autoregressive process. Luo et al. (2001) obtained better estimates of genetic parameters for a threshold model applied to a categorical trait when herd-year-season effects were treated as random rather than fixed effects.
All countries with genetic evaluations for clinical mastitis or other clinical disease traits assumed normally distributed observations in their genetic evaluation models. Research has demonstrated that improvements can be achieved by analyzing mastitis with threshold, random regression, and survival models. Mixture (Detilleux and Leroy, 2000) and negative binomial models (Tempelman and Gianola, 1996) have also been suggested, but they are currently too "computer demanding" to be considered for genetic evaluations based on large-scale field data and will not be discussed further here.

Threshold models are theoretically better than linear Gaussian models for analysis of binary and categorical data (e.g., Gianola, 1982; Mäntysaari et al., 1993). Practical implementations confirm that substantially higher heritabilities are obtained when using a threshold model compared with a linear Gaussian model. Kadarmideen et al. (2000) estimated a heritability of 0.038 for clinical mastitis using a linear sire model and of 0.168 when using a threshold model with similar explanatory effects. They found similar tendencies for other disease traits and for fertility traits. Weller et al. (1988) and Boettcher et al. (1999) found that heritability estimates were higher for calving and binary longevity traits, respectively, when analyzed with a threshold model compared with a linear model.

Boettcher et al. (1999) also compared breeding values of bulls for longevity when analyzed with a linear, threshold, and proportional hazard sire model. There was good agreement between breeding values obtained with the linear and threshold models (correlation between breeding values was 0.98). In comparison, the correlation ranged from 0.90 to 0.94 and 0.85 to 0.90 when breeding values obtained with proportional hazard models were compared with the linear and threshold model, respectively. The threshold and proportional hazard models (as implemented in the Survival Kit; Ducrocq and Sölkner, 1994) required roughly 5 to 10 times more computer time than did the linear model.

Random regression. Random regression models were applied for genetic evaluations of SCC and milking speed as well as dairy production traits, but could in principle be applied to any trait being measured over time. Veerkamp et al. (2001) applied and discussed advantages of applying random regression models to survival data. Schaeffer (2004) discussed the use of random regression models for fertility and other longitudinal traits. Coffey et al. (2003) analyzed conformation traits and daughter energy balance using random regression. Rekaya et al. (1998) analyzed the absence or presence of clinical mastitis in different time periods during lactation using random regression. 
The advantage of random regression models is the ability to account for time aspects and multiple treatments as well as allowing for the trait to change genetically over time while accounting for different nongenetic effects affecting the trait of interest (e.g., at different stages of lactation). For example, gene expression for clinical mastitis varies considerably during the course of lactation (e.g., Lund et al., 1999; Heringstad et al., 2003). Using a small Holstein dataset, Rekaya et al. (2003) showed that a random regression model was superior to a similar model with constant genetic value over time based on Bayes factor. Imposing a firstorder autoregressive structure for residual variances for the random regression model further improved results.

It was interesting to note that test-day models were more frequently applied to SCC than to dairy production (Table 3). The relative increase in heritability when changing from a lactation-sum model to a test-day model was larger for SCC than for dairy production traits for many countries submitting such evaluations to routine international genetic evaluations. Furthermore, across-country genetic correlations with clinical mastitis typically increased when a test-day model was used compared with a lactation-sum model, which suggests that taking the shape of the lactation curve into account yields a measure that is closer to the true breeding goal for resistance against mastitis in many countries.

Functions that are optimal for fitting lactation curves for production traits are not necessarily optimal for SCC curves. The SCC profiles usually are not smooth during the course of lactation and the cell count usually increases dramatically in connection with mastitis infections, which makes the SCC curve difficult to describe with a simple function. Gengler and Mayers (2003) associated large residuals from a random regression test-day model for SCC with high likelihood of mastitis infection, and used this likelihood as a weight on the concerned SCC observation. As a result the genetic correlations of SCC with resistance to clinical mastitis in the Nordic countries were higher for Belgium that used the weighted random regression testday model than all other participating countries in Interbull udder health evaluations (0.65 vs. 0.59 on average).

Survival vs. linear models. Application of linear random regression models might not be optimal for traits with discrete phenotypic expression (e.g., survival and clinical mastitis), but would allow for prediction of breeding values for both cows and bulls while considering time aspects, censored records, and predictive information from correlated traits. Satisfactory longevity breeding values for both cows and bulls can, however, be obtained with an approximate Weibull Animal model (Ducrocq, 2001). The ability to account for changing genetic background during the course of an animal's life is another advantage of random regression compared with the traditionally applied survival models. However, a survival model with different baseline hazards (i.e., depending on parity and stage of lactation within parity) has recently been developed and implemented for the French genetic evaluation for length of productive life (Ducrocq, 2002, personal communication 2004). Advantages of random regression models also include the ability to account for repeated observations and analyzing multiple traits simultaneously.

Simulation results by Schneider et al. (2003) indicated that survival analysis is more appropriate to analyze fertility interval measures than a linear sire model with similar fixed effects. Survival analysis could be extended to an animal model, but such a model would be very demanding computationally. VanRaden (2003) indicated that a linear animal model could yield more reliable breeding values compared with a nonlinear sire model for analysis of longevity and fertility traits following a binary distribution. The extra information gained from maternal relatives is especially important for low heritability traits such as fertility.

Carlén et al. (unpublished data, 2004) analyzed clinical mastitis data with both a survival model and a linear sire model including the same effects. The dependent variable in the survival analysis was clinical mastitis from $10 \mathrm{~d}$ before calving to the day of first treatment of mastitis or culling due to mastitis (uncensored records). For cows without mastitis, the records were considered censored, and the time period was defined as the number of days from $10 \mathrm{~d}$ before calving to either the day of next calving, the day of culling for reasons other than mastitis, the day of movement to a new herd, or to lactation $d$ 140. The time period was restricted to a maximum of $700 \mathrm{~d}$. The dependent variable in the linear sire model was the incidence of clinical mastitis (binary trait) from $10 \mathrm{~d}$ before calving to $150 \mathrm{~d}$ after calving. The heritability on the original scale for the survival model was 0.04 compared with 0.03 for the linear sire model. A disadvantage of this approach compared with random regression is that the survival model does not account for multiple mastitis cases.

Many suggested models would likely improve current practices. But often there is not sufficient scientific evidence available to indicate which of the alternative suggestions are best. Whereas suggested research can lead to improvements in applied genetic evaluations for functional traits, it is also clear that genetic analysis of functional traits is in itself an area where more research should be done. 


\section{Across-Country Genetic Correlations}

The across-country genetic correlations in Table 4 could differ from unity because of differences in trait definitions, data included, evaluation procedures, and because of genotype $\times$ average-country-environment interaction. Furthermore, differences in national genetic evaluation procedures, weak genetic ties and erroneous identification may also cause correlations lower than unity. Therefore, correlations in Table 4 partly reflect how well traits and evaluation procedures have been harmonized. The 7 core populations were all well connected and estimated genetic correlations between these countries were reliable. This was not always the case for all populations.

Differences in trait definitions alone could not explain the low correlations observed between similar longevity traits measured in different countries. The low correlations may reflect differences in trait definitions and in culling reasons. Another explanation could be problems with estimating genetic trends in some applications using time dependent effects (Nielsen et al., 2003). Calving ease in different countries was more closely correlated than longevity, but the estimated correlation also varied considerably.

Moderate to high genetic correlations among different female fertility traits measured in Nordic Holstein populations were estimated by Mark et al. (2001). Harmonization in trait definitions, data included, and evaluation procedures could lead to higher genetic correlations for female fertility. Across-country genetic correlations for other traits were not available.

\section{CONCLUSIONS}

This survey of genetic evaluations in dairy cattle included information from 31 Interbull member countries. These countries were expected to represent countries with the most developed evaluation systems. From the survey, it was evident that countries have prioritized very differently in developing national genetic evaluations. There was substantial variation in the number of traits and trait groups considered per country (many countries lacked genetic evaluations for one or more economically important trait), the data edits per trait and country, trait definitions per trait and country, genetic evaluation procedure per trait and country, the way of accounting for variance heterogeneity, modeling of genetic effects, and the frequency and treatment of explanatory effects in genetic models.

There was much room for improvement in methodology applied for genetic evaluations and especially for functional traits such as udder health. Female fertility and workability traits were commonly evaluated in many Interbull member countries and could be next in line for Interbull to consider in international genetic evaluations.

\section{ACKNOWLEDGMENTS}

I am grateful to national dairy cattle genetic evaluation units for all the effort they put into providing the information necessary for this study and to my colleagues at the Interbull Centre for valuable discussions.

\section{REFERENCES}

Banos, G., and A. Sigurdsson. 1996. Application of contemporary methods for use of international data in national genetic evaluations. J. Dairy Sci. 79:1117-1125.

Boettcher, P. J., L. K. Jairath, and J. C. M. Dekkers. 1999. Comparison of methods for genetic evaluation of sires for survival of their daughters in the first three lactations. J. Dairy Sci. 82:1034-1044.

Coffey, M. P., G. Simm, W. G. Hill, and S. Brotherstone. 2003. Genetic evaluations of dairy bulls for daughter energy balance profiles using linear type scores and body conditioning score analyzed using random regression. J. Dairy Sci. 86:2205-2212.

de Jong, G., and A. G. F. Harbers. 2002. Determining changes in definition of conformation traits and effects on international evaluations. Interbull Bull. 29:39-42.

Detilleux, J., and P. L. Leroy. 2000. Application of a mixed normal mixture model for the estimation of mastitis related parameters. J. Dairy Sci. 83:2341-2349.

Ducrocq, V. 2001. A two step procedure to get animal model solutions in Weibull survival models used for genetic evaluations on length of productive life. Interbull Bull. 27:147-152.

Ducrocq, V. 2002. A piecewise Weibull mixed model for the analysis of length of productive life of dairy cows. Pages 505-508 in Proc. 7th World Cong. Genet. Appl. Livest. Prod., Montpellier, France.

Ducrocq, V., and J. Sölkner. 1994. "The Survival Kit", a Fortran package for the analysis of survival data. Pages 51-52 in Proc. 5th World Cong. Genet. Appl. Livest. Prod., Guelph, Canada.

Gengler, N., and P. Mayers. 2003. Use of a weighted random regression test-day model to better relate observed somatic cell score to mastitis infection likelihood. Interbull Bull. 31:92-96.

Gianola, D. 1982. Theory and analysis of threshold characters. J. Anim. Sci. 54:1079-1096.

Groen, A. F., T. Steine, J. J. Colleau, J. Pedersen, J. Pribyl, and N. Reinsch. 1997. Economic values in dairy cattle breeding, with special reference to functional traits. Report of an EAAP-working group. Livest. Prod. Sci. 49:1-21.

Harville, D. A., and R. W. Mee. 1984. A mixed-model procedure for analyzing ordered categorical data. Biometrics 40:393-408.

Heringstad, B., Y. M. Chang, D. Gianola, and G. Klemetsdal. 2003. Genetic analysis of longitudinal trajectory of clinical mastitis in first-lactation Norwegian cattle. J. Dairy Sci. 86:2676-2683.

Hoeschele, I., and B. Tier. 1995. Estimation of variance components of threshold characters by marginal posterior modes and means via Gibbs sampling. Genet. Sel. Evol. 27:519-540.

Interbull. 1996. Sire evaluation procedures for non-dairy and growth and beef production traits practiced in various countries. Interbull Bull. 13.

Interbull, 2000. National genetic evaluation programmes for dairy production traits practiced in Interbull member countries. Interbull Bull. 24.

Interbull. 2001. Interbull guidelines for national and international genetic evaluation systems in dairy cattle with focus on production traits. Interbull Bull. 28.

Jakobsen, J. 2003. Effect of right and left censoring of longevity records as input to Mace. Available: www.interbull.org. Accessed Nov. 10, 2003.

Jakobsen, J., U. Emanuelson, W. F. Fikse, H. Jorjani, and T. Mark. 2003. Status of Mace for calving traits. Available: www.interbull. org. Accessed Nov. 10, 2003. 
Jensen, J. 2001. Genetic evaluation of dairy cattle using test-day models. J. Dairy Sci. 84:2803-2812.

Kadarmideen, H. N., R. Thompson, and G. Simm. 2000. Linear and Threshold model genetic parameters for disease, fertility and milk production in dairy cattle. Anim. Sci. 71:411-419.

Kolmodin, R., E. Strandberg, P. Madsen, J. Jensen, and H. Jorjani. 2002. Genotype by environment interaction in Nordic dairy cattle studied using reaction norms. Acta. Agric. Scand., Sect. A. Anim. Sci. 52:11-24.

Lund, M. S., J. Jensen, and P. H. Petersen. 1999. Estimation of genetic and phenotypic parameters for clinical mastitis, somatic cell production deviance and protein yield in dairy cattle using Gibbs sampling. J. Dairy Sci. 82:1045-1051.

Luo, M. F., P. J. Boettcher, L. R. Schaeffer, and J. C. M. Dekkers. 2001. Bayesian inference for categorical traits with an application to variance component estimation. J. Dairy Sci. 84:694-704.

Mäntysaari, E. A., R. L. Quaas, and Y. T. Grohn. 1993. Simulation study on covariance component estimation for two binary traits in an underlying continuous scale. J. Dairy Sci. 74:580-591.

Mark, T., U. S. Nielsen, J. Pösö, M. Gundel, and M. Svendsen. 2001. Genetic relationships among functional traits in the Nordic Holstein populations. Interbull Bull. 27:64-67.

Meuwissen, T. H. E., G. de Jong, and B. Engel. 1996. Joint estimation of breeding values and heterogeneous variances of large data files. J. Dairy Sci. 79:310-316.

Nielsen, U. S., O. M. Pedersen, and M. Toivonen. 2003. Time dependent effects as source of bias in estimating breeding values for longevity and fertility traits. Interbull Bull. 30:29-34.

Ramirez-Valverde, R., I. Misztal, and J. K. Bertrand. 2001. Comparison of threshold vs linear and animal vs sire models for predicting direct and maternal genetic effects on calving difficulty in beef cattle. J. Anim. Sci. 79:333-338.

Rekaya, R., D. Gianola, K. Weigel, and G. Shook. 2003. Longitudinal random effects models for genetic analysis of binary data with application to mastitis in dairy cattle. Genet. Sel. Evol. $35: 457-468$.
Rekaya, R., S. L. Rodriguez-Zas, D. Gianola, and G. E. Shook. 1998. Test-day models for longitudinal binary responses: an application to mastitis in Holsteins. Page 44 in Book of Abstracts 49th Annu. Mtg. of EAAP. Wageningen Pers, Wageningen, The Netherlands.

Robert-Cranié, C., B. Bonaïti, D. Boichard, and A. Barbat. 1999. Accounting for variance heterogeneity in French dairy cattle genetic evaluation. Livest. Prod. Sci. 60:343-357.

Schaeffer, L. R. 1994. Multiple-country comparisons of dairy sires. J. Dairy Sci. 77:2671-2678.

Schaeffer, L. R. 2004. Application of random regression models in animal breeding. Livest. Prod. Sci. 86:35-45.

Schneider, M. del P., E. Strandberg and A. Roth, 2003. Survival analysis applied to genetic evaluation for fertility in dairy cattle. Page 55 in book of Abstracts 54th Annu. Mtg. of EAAP. Wageningen Pers, Wageningen, The Netherlands.

Sullivan P. G., and L. R. Schaeffer, 1994. Fixed versus random genetic groups. Pages 483-486 in Proc. 5th World Cong. Genet. Appl. Livest. Prod., Guelph, Canada.

Tempelman, R. J., and D. Gianola. 1996. A mixed effects model for overdispersed count data in animal breeding. Biometrics 52:265-279.

van Bebber, J., N. Reinsch, W. Junge, and E. Kalm. 1997. Accounting for herd, year and season effects in genetic evaluations of dairy cattle: A review. Livest. Prod. Sci. 51:191-203.

VanRaden, P. M. 2003. Longevity and fertility trait definitions compared in theory and simulation. Interbull Bull. 30:43-46.

Veerkamp, R. F., S. Brotherstone, B. Engel, and T. H. E. Meuwissen. 2001. Analysis of censored survival data using random regression models. Anim. Sci. 72:1-10.

Visscher, P. M., and M. E. Goddard. 1993. Fixed and random contemporary groups. J. Dairy Sci. 76:1444-1454.

Weller, J. I., I. Misztal, and D. Gianola. 1988. Genetic analysis of dystocia and calf mortality in Israeli-Holsteins by threshold and linear models. J. Dairy Sci. 71:2491-2501.

Wiggans, G. R., and P. M. VanRaden. 1991. Method and effect of adjustment for heterogeneous variance. J. Dairy Sci. 74:43504357. 